\title{
Topic Articles
}

\section{Reflexivity, Realism, and Consciousness}

\author{
Rory Madden | ORCID: 0000-0002-2791-0747 \\ Department of Philosophy, University College London, London, UK \\ r.madden@ucl.ac.uk
}

\begin{abstract}
The author raises a puzzle about the compatibility of the two features which, according to Ayers, jointly characterize paradigmatic cases of seeing, viz. 'perspicuity' and 'immediacy'. In Section 1, the author explains why Ayers's explanation of these two features suggests an inconsistent combination of reflexivity and realism about sense experience. Some of Ayers's comments about our awareness of causation suggest a way of giving up on reflexivity. In Section 2, the author uses a thought-experiment to support the view that realism rather than reflexivity ought to be given up. In Section 3 , the author gives a further reason for Ayers to take this option: it furnishes a response to a troublesome challenge concerning the epistemic significance of consciousness, a challenge which Ayers himself anticipates at the end of Chapter 2 of Knowing and Seeing but does not fully resolve.
\end{abstract}

\section{Keywords}

Ayers - knowledge - perception - reflexivity - realism - consciousness

The second chapter of Knowing and Seeing, 'Perception and Primary Knowledge', defends foundationalism, specifically 'the traditional view of 
anti-sceptical empiricists that the deliverances of the senses are intrinsically authoritative' $(2019,34)$. For the senses to be intrinsically authoritative, as I understand the phrase, is for the senses to be a source of knowledge independently of extrinsic justification or extraneous evidential support. Something about sensory perception in itself is enough to move us to knowledge.

Ayers's explanation of the authority of the senses, however, departs from tradition. Ayers insightfully draws our attention to the fact that the intrinsic character of sensory experience is richer than early modern writers typically allowed. An ordinary episode of sensory experience is in itself a complex situation, which coherently integrates the deliverances of distinct sense modalities to present environmental objects in spatial and causal relations to each other. An explanation of the intrinsic authority of the senses, then, need not restrict itself to qualities like vivacity or involuntariness. The empiricist foundationalist can appeal to the possession by individual sensory episodes of the kind of virtues that coherentists have traditionally ascribed to beliefs collectively, such as integration and consistency.

But there is more to Ayers's explanation of the authority of the senses than coherentism in microcosm. His phenomenological reflections suggest that the rich, integrated character of ordinary sense experience, has also what one might call a reflexive aspect: 'the perceptual relation is itself an object of perceptual awareness' (2019, 34); 'we are perceptually aware, at a practical level, of the causal relation between the object of perception and our experience of it ...' $(2019,54) ; '$ '.. when we see an object we are thereby perceptually aware of our seeing it ...' $(2019,55)$; 'we are perceptually aware of the causal relation between the object and ourselves' (ibid.); 'perception of those objects ... comes with a broad perceptual awareness of the causal relation they have to us, i.e. to our sense-organs' (2019, 57); 'in being perceptually aware of our environment, we are at the same time aware of how it is that we are aware of it' $(2019,194)$. Ayers's position is that sensory experience is, in some sense, part of its own subject matter.

The reflexivity of sensory experience figures in the explanation of the 'perspicuity' of paradigm cases of knowledge based upon sensory experience. Paradigm cases of perceptual knowledge are perspicuous in the sense that one knows that, and to some extent how, one knows. And the explanation is that in undergoing an episode of sensory experience, one is not only aware of environmental objects but aware of them as causally generating the very episode in question. Hence one knows to some extent how one knows about these objects when one knows about them on the basis of sense experience.

Ayers connects perspicuity to the intrinsic authority of the senses. But what exactly is the connection? The underlying principles of the argument are not 
explicit but there is some immediate plausibility to the idea that this genre of intrinsic reflexive content at least enhances the authority of an epistemic source. Consider by way of analogy a written report about some worldly events. Suppose the report includes a narrative about how the report itself came to be written, an account which makes clear how the writing of the report was appropriately sensitive to the worldly events. Then such a report seems, at the very least, less in need of extraneous evidential support than an isolated report which brutely details some worldly events without giving its reader any sense of how its author could have been in a position to know of the events. It is not impossible for a written report with a reflexive self-explanatory character to be bogus. But, ceteris paribus, it's a safer bet than a report which lacks this character.

Now, the self-explanatory written report is like paradigmatic sensory knowledge in respect of its intrinsic reflexivity. But it is unlike the sensory paradigm in another respect. Although the consumer of the self-explanatory report does have a decent sense of the route by which knowledge of the events is acquired, they are learning of the events at more than one degree of remove: via the inscriptions before their eyes, which are derived from the author's earlier acts of writing and acts of recall, which in turn are derived from some earlier more direct contact with the events. That is, the written testimony lacks the second feature which Ayers ascribes to the source of paradigmatic sensory knowledge, the feature of 'directness' or 'immediacy'. Sense experience, we are told, is 'direct cognitive contact with independent objects of knowledge' (2019, 28). It is a 'transparent', 'clear glass window' on the environment (2019, 35); 'the immediate object of perceptual awareness is independent reality, including oneself, and not some 'internal' image or representation' (2019, 194).

But what precisely do these ideas come to? I'm not confident. But Moore's name is invoked, and talk of 'independent reality' and 'transparency' is suggestive of two theses about sense experience which are associated with Moore's famous 1903 'Refutation of Idealism'.

First, anti-Berkeleian realism about sensory awareness and its objects: if one undergoes an episode of sensory awareness $e$, and $o$ is an object of $e$, then $o$ exists independently of the occurrence of $e$.

The second thesis we can call transparency: in reflecting introspectively on the character of an episode of sense experience one is only able to attend to objects of the sense experience.

Combining realism and transparency, one arrives at the realist transparency view that in reflecting introspectively on the character of an episode of sense experience one is only able to attend to objects which exist independently of that episode of sense experience. 
Now, how does this direct realist notion of immediacy relate to perspicuity? Ayers assures us that the two features 'fit very well together' (2019, viii). They are 'corollary' $(2019,27)$. However, it strikes me that there is a prima facie case for the opposite view that they do not fit at well together. In particular the components of reflexivity and realism seem to me to be in tension.

For suppose that an ordinary sense experience $e$ has reflexive character. Then $e$ is among the objects of $e$. Then $e$ has an object which does not exist independently of $e$. For $e$ does not exist independently of itself. Realism: any object of $e$ exists independently of $e$. Contradiction.

To put the puzzle another way: if experience is nothing but a transparent window on an independently existing reality, then how could it possibly also tell us about itself?

I think this is a real puzzle. One or both of reflexivity and realism must be given up.

On the face of it, Ayers's explanation of the perspicuity of sensory knowledge is committed to the reflexivity of sense experience. In having a sense experience, one is ipso facto aware of the causation of the experience by its environmental objects. And the following principle - call it the dissectivity of causal awareness-looks plausible: if an experience $e$ makes one aware of a causal relation between $x$ and $y$ then $e$ is awareness of $x$ and $e$ is awareness of $y$. So, if $e$ makes one aware of a causal relation between $e$ and its environmental objects, then $e$ is awareness of $e$, as well as awareness of its environmental objects. Sense experience is reflexive.

One way of resisting this result would be to hold that one is aware of the causation of $e$ by $o$, but one is made aware of it through some distinct higherorder experience $e^{\prime}$ which takes $e$ as one of its objects. This theory respects the realist thesis that the object of experience is always some distinct existence and thereby stops short of strict reflexivity. Indeed, when early analytic philosophers under the influence of Moore's realism wrote about experience of experience, this higher-order option was typically assumed. Here is Russell's depiction of introspective experience in his 1913 Theory of Knowledge manuscript (Russell 1984, 38). The notation '- $A$-' represents the dual relation of acquaintance between subject and object: ${ }^{1}$

$$
S^{\prime}-A-(S-A-O)
$$

But Russell's own notation brings out an inherent absurdity of this realist evasion of strict reflexivity. Nothing guarantees that you, the introspecting subject

1 This is a slight simplification of Russell's depiction, which specifies that the outer, introspective, occurrence of acquaintance is the 'presence' species of acquaintance ' $-\mathrm{P}$-'. 
$S^{\prime}$, are identical with the subject $S$ of the experience of which you are aware. This means that it should be possible to make a mistake about whether you yourself are the subject of an experience which you are now introspecting. But this does not seem to be possible. ${ }^{2}$

The higher-order view appears to make a further false prediction. Again assuming that awareness is 'dissective', it would follow that in having a higherorder experience $e^{\prime}$ directed upon an experience $e$ directed upon external object $o$, one would thereby be aware of the external object $o$. But given that $e$ was already an experience of $o$, the higher-order view predicts that one has two experiences of the same external object. But there never seems to be this sort of duplication of awareness. ${ }^{3}$

On the other hand, if experience is awareness of itself, then neither problem can arise. The awareness and the experience are one thing and not two. So the subject of the awareness of the experience cannot possibly be distinct from the subject of the experience. Neither can the awareness be a second act of awareness which duplicates the experience of the external object.

Russell rejects reflexivity but maintains the general thesis that an experience can be the object of (some) experience. Aspects of Ayers's discussion in Chapter 2 suggest a way for the realist to explain perspicuity without relying on even that general thesis.

I think it is fair to say that Ayers's text is unsettled (or perhaps just pluralistic) about what one might call the 'subjective relatum' of the causal relations presented in sensory experience. At points it is the causation of the experience itself which is said to be given in experience $\left(2019,53^{-} 54\right)$. But at other points it is the causal relation to the self which is invoked (to 'us', 'the perceiver', 'the subject is self-perceived in relation to things in the perceived environment' $2019,45)$, and elsewhere causal relations to 'organs of sense' (2019, 40) - eyes, skin, ears, etc.- -are emphasised.

Now on any plausible theory of the self, the self exists independently of any particular act of sensory experience. This is clearest in bodily and animalist theories, but it follows from any theory short of G. Strawson's theory that

2 In Shoemaker's well-known terminology, introspection-based judgements are logically and not just de facto immune to error through misidentification relative to ' $\mathrm{I}$ '.

3 Aristotle makes this 'duplication' argument against the view that one perceives one's seeing or hearing via some other sense than the seeing or hearing itself (De Anima: 3.2). See Textor 2017 , Chapter 4 for discussion of Brentano's adoption of this argument. 
each transient pulse of experience supports its own short-lived self (Strawson 2009). And sense-organs are clearly no more experience-dependent than any other part of the body. So, if perspicuity could be explained by awareness of the causal relation between (distal) objects and the abiding self or its sense organs, then Ayers could hold on to realism and backtrack on strict reflexivity. One is aware of experience-independent objects and their causal relations and that's it. It's just that some of the relata are, so to speak, right under one's nose (on occasion, literally one's nose). The awareness of causation which makes perceptual knowledge perspicuous is just a special case of awareness of causation among outer things.

However, I want to sketch a thought-experiment-I hope very much in the spirit of Ayers's own phenomenological reflections - to indicate why this cannot be a complete account.

Suppose on Monday there occurs an episode of sensory experience of the world in which some moving array of environmental objects causally affect one's sense organs in the normal way. Moreover, the spatio-causal process by which one's sense organs are being affected by the environmental objects is itself something to which the sense organs, collectively and over the course of the extended episode, are sensitive in the ways Ayers insightfully brings out; one's sense organs and their interactions with the environment are themselves within the multimodally perceived scene. But now suppose the following deviant causal chain is spliced into an early stage of perceptual processing for the duration of the episode. The afferent signals from one's sensory organs, including one's proprioceptive muscle-spindles, are tapped, and recorded in their totality. This information is stored for a whole day before being allowed to resume a normal journey into one's brain. Lying still in one's dark laboratory bed on Tuesday, one is thereby induced to undergo an episode of sensory experience, subjectively just Monday's embodied multimodal episode.

It strikes me as obvious that there would be something illusory about Tuesday's episode. But what? The episode is perfectly faithful to the environmental objects and events on Monday. And — here is the important point-it is equally faithful to the spatio-causal relations which obtained on Monday between these objects and one's abiding material self and its sense organs. Not only was there really, say, a stick. It really did press against and deflect one's fingers in just the way it now seems to.

I propose that the episode would be residually illusory in the following respect. In undergoing the experience, it ipso facto seems to one that these environmental objects and events are simultaneous with, and causally sustaining as it unfolds, the very experience that one is undergoing. On Tuesday these environmental objects and events are not simultaneous with, and causally sustaining as it unfolds, the very experience that one is then undergoing. 
That's the respect in which the experience is non-veridical. That one's experience bears these relations to distal objects is not just something one believes or assumes, extraneous to undergoing the experience itself. For we can stipulate that one knows perfectly well about the strange situation when one is in it on Tuesday. So one would not then have the belief that these objects and events are simultaneous with and causally sustaining the very experience one is now undergoing. And yet, I submit, this is still how things would seem simply in virtue of having the experience. One would still have that sense of the causal and temporal presence of the scene.

If this is right, then the phenomenology of sense experience presupposes reflexivity. The right model is not a Russellian realist higher-order experience model on which the causation of an experience is presented by some distinct experience (see Figure 1).

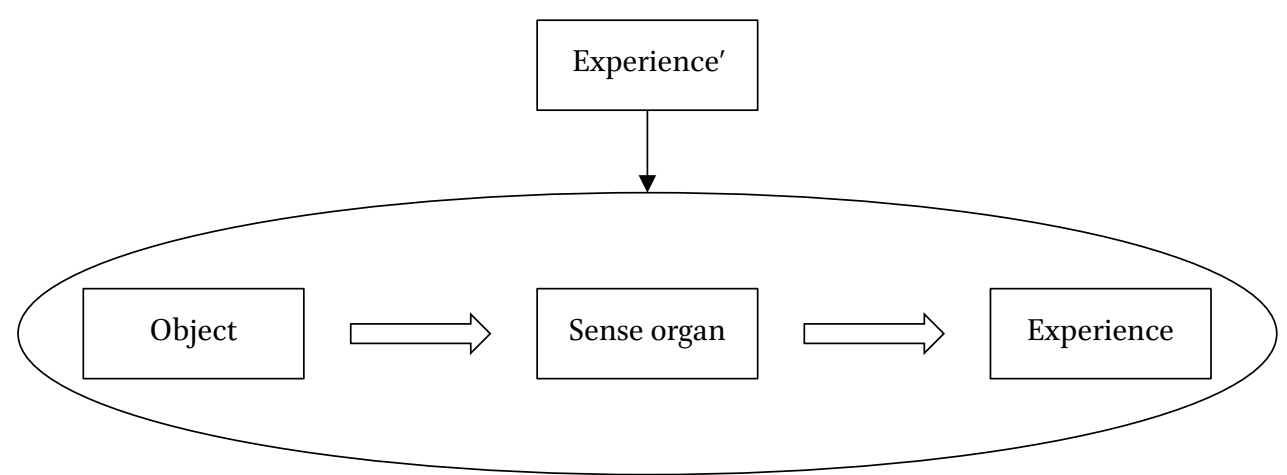

FIGURE 1 A Russellian model

Nor, our thought experiment now suggests, should we accept the realist theory that only the non-experiential phase of the causal process generating an experience is presented in that experience (see Figure 2).

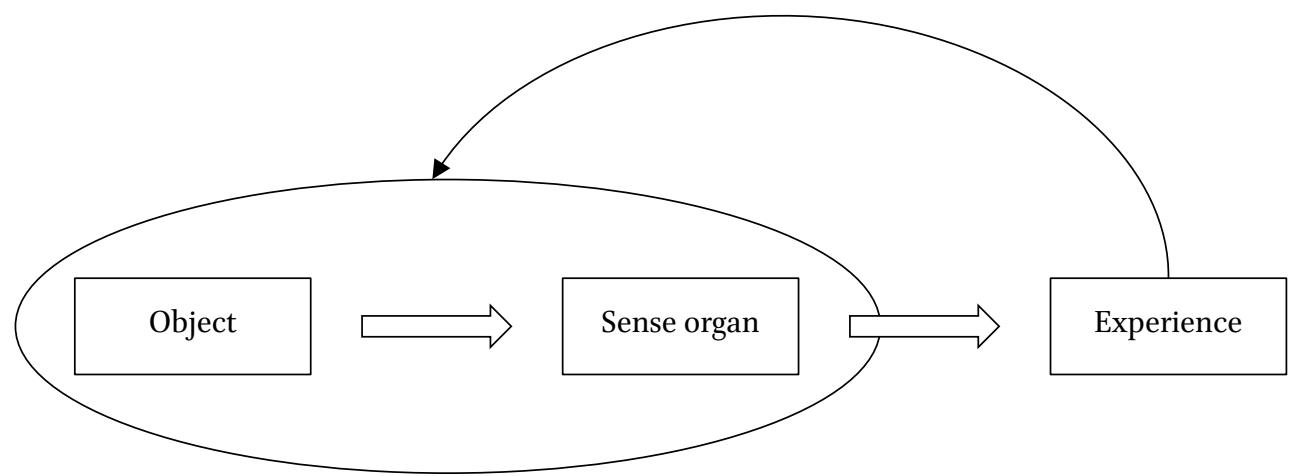

FIGURE 2 A realist model 
The right thing to say is that a relational situation running all the way from object to experience is presented in that very experience (see Figure 3).

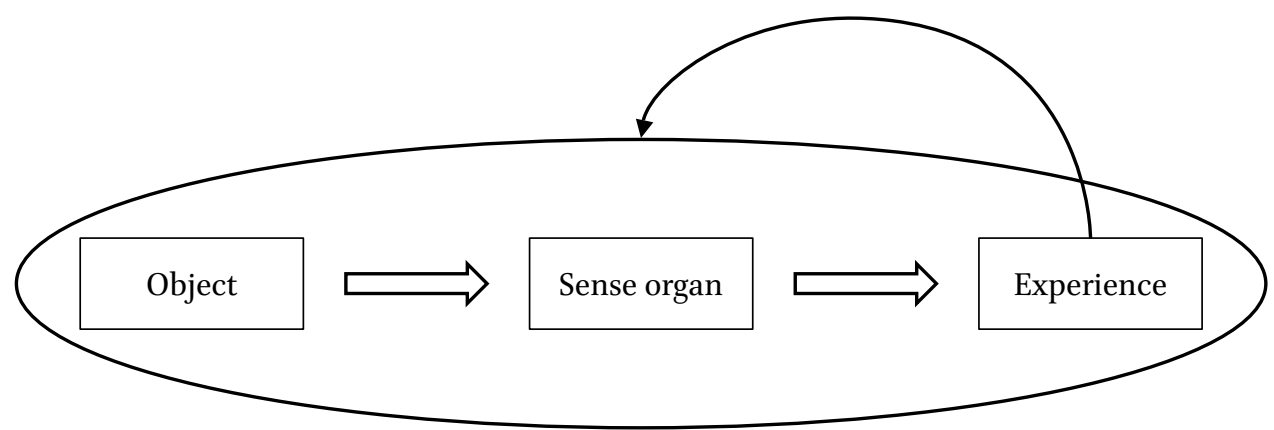

FIGURE 3 A reflexive model

Assuming the dissective principle that the relata of the presented situation must in turn be presented, it follows that an ordinary sensory experience has itself among its objects. So, I think Ayers must moderate his sympathy for Moorean realism. It is not true that sense experience is nothing but a transparent window on an independently existing reality.

However, there is much that is salvageable in the vicinity of Moorean realism. We have to reject the realist claim that, if one undergoes an episode of sense awareness $e$, and $o$ is an object of $e$, then $o$ exists independently of the occurrence of $e$. For $e$ itself is a counterexample in central cases. But nothing said so far is incompatible with the following thesis of moderate realism: if one undergoes an episode of sense awareness $e$, then there is some $o$ such that $o$ is an object of $e$ and $o$ exists independently of the occurrence of $e$. According to this more moderate thesis, sense experience is at least a window on an independently existing reality. Sense experience cannot solely present a subjective internal 'image' dependent for its existence upon the occurrence of that experience. Still less can an experience be its own sole object.

It is also worth noting that the falsity of realist transparency as stated earlier does not immediately follow from reflexivity and the attendant falsity of realism. For even if sense awareness counts awareness among its objects, perhaps external things remain the only possible objects of selection by the subject's attention. This appears to be Brentano's contention: while awareness is 'of itself on the side', awareness cannot be made the object of 'observation'.

However, it seems to me that Ayers's own phenomenological reflections in Chapter 2 also put serious pressure on this Brentanian contention. One can 
exploit one's practical grasp of the causal enabling conditions of visual experience, by wiggling one's head for example, precisely to intentionally manipulate one's visual experience, while having zero interest in the presumably unchanging distal objects. If that's not sufficient for attending to one's visual experience then I don't know what 'attending' means. So I think Ayers should reject realist transparency as well.

\section{3}

\section{Consciousness}

I want to end by suggesting a further advantage to Ayers of embracing the full-blooded reflexivity of sense experience and not settling for a realist ersatz on which sense organs stand in for sense experience in making sense experience perspicuous.

Ayers endorses the thesis that primary seeing is conscious seeing. But why? What is the essential connection between immediate, perspicuous seeing, and consciousness?

At the end of Chapter 2, Ayers in effect anticipates a sort of 'superblindsight' thought-experiment which challenges the significance of consciousness:

Let us suppose that the cognitive connection with their environment necessary for any subjects to have knowledge of it and of their own action (if it can be called action) within it, is entirely through secondary perception such as blindsight or subliminal perception, but total. Suppose that such unconscious sensory input gave rise in them to a kind of ongoing, coherent, more or less comprehensive grand Hunch about their environment, confident and true. (Ayers 2019, 68)

The challenge develops this superblindsight case by further enriching the content of the superblindsighted subject's Hunch to concern not only the environment but also their spatio-causal relationship to it (ibid, 69):

My account of the 'evidence' of perceptual knowledge, however, which has concentrated on its content, might wrongly be taken to suggest that nothing of epistemological significance is lacking in the supposition that a subject could have only secondary, 'unconscious' knowledge provided that it is explicitly built into it that subjects have true beliefs with the relevant content. That is, if it is stipulated that they have true beliefs not only about their environment but about their spatio-causal relationship to their environment-indeed, that they have true beliefs about how they come to believe truly what they believe. 
Ayers response to this, as far as I can make it out, is simply to insist on the position that consciousness is crucial for primary (immediate and perspicuous) knowledge (ibid):

Yet all that that stipulation of belief would do is to put our imaginary person into a roughly similar position to that of a blind-sighted person ... The conscious awareness of how the observed object or state of affairs is affecting us perceptually that comes with normal perception of an object or state of affairs cannot be replaced without epistemic loss simply by supplying the subject in our thought-experiment with a set of 'blind' true beliefs having the same content and external cause as the awareness, and as reliably generated. Primary knowledge is not just caused, but is also consciously grounded, and primary perceptual knowledge is grounded in its objects as they are perspicuously presented or revealed in sense perception in their changing spatio-causal relationship to the subject.

But the question still stands: why must primary knowledge be 'consciously grounded'? Exactly what 'epistemic loss' would be entailed by lack of a conscious source? Ayers himself gives blindsight and subliminal perception as examples of 'secondary seeing' that lack perspicuity but possesses immediacy (thus 'secondary' in an inverse way to the self-explanatory written testimony considered in $\S 1$ above). So the view cannot be that consciousness is required for immediacy. So the view must be that consciousness is required for objects to be 'perspicuously presented'. But why? Ayers appears to concede that the superblind states could have all the same content as conscious perceptual experience, including even content about objects' 'changing spatio-causal relationship to the subject'. Hence, he tries to shift our focus away from content altogether in order to convince us that consciousness is required for perspicuous presentation. But it is not clear what we are being asked to concentrate on instead. Some intrinsic qualitative glow which possibly does, and possibly does not, supplement a given content? Even if there were such a thing, what would it have to do with perspicuous presentation?

I think a way forward for Ayers emerges when we look more closely at the analysis of consciousness.

'Consciousness' has at least two meanings in contemporary philosophy. The first is basically equivalent to 'awareness'. One is conscious of the table if and only if one is aware of the table. The other use, which I think is more traditional in philosophy, modifies states, episodes, and actions of a subject. One 
has conscious states. One undergoes and does things consciously. Ayers almost invariably adheres to this second more traditional way of speaking.

A number of writers have taken the (as it seems to me plausible) position that the first kind of consciousness in effect can be used to elucidate the second kind of consciousness, as follows: a conscious state, episode, or action is a state, episode, or action of which its subject is aware. Theories divide at this point. Perhaps most well-known is Rosenthal's 'higher-order thought' theory, which analyses a subject's awareness of their own state in broadly intellectual terms: a state is conscious just in case it is accompanied by a higher-order thought to the effect that one is in that state (Rosenthal 2002). But this theory ought to be unacceptable to Ayers, who holds that nonhuman animals have conscious states $(2019,68)$. Nonhuman animals don't have first person thoughts about their own states of mind.

But what is the alternative? Higher-order thought theories are often opposed to 'higher-order perception' theories, according to which a state is conscious just in case it is the object of a higher-order experience of the state. In principle, animals could be in such higher-order states even if they are incapable of articulating them conceptually. In that respect, a higher-order perception theory is less chauvinistic than a higher-order thought theory. But it is still unsatisfactory in various ways. We have already seen some difficulties with the idea of higher-order perceptions. Moreover, to halt an infinite regress of higher-order perceptions there must be some unconscious higher-order perception ultimately grounding the consciousness of one's states. This strikes me as a far-fetched consequence of the theory, even if, inherently, a difficult one to falsify directly.

We might add that both higher-order theories are inconsistent with the conjunction of two of Ayers's commitments. Ayers holds the foundationalist thesis that some sense experience is intrinsically authoritative; and as we have just seen he holds that consciousness is necessary for authority. It follows that some sense experience must be intrinsically conscious. But according to a higher-order theory, a sense experience is conscious in virtue of being accessed by an extrinsic higher-order episode. According to the theory, then, no sense experience is intrinsically conscious.

How to proceed? I have suggested by means of a thought experiment that the best account of the Ayersian perspicuity of sense experience is committed to the reflexivity of sense experience. Thus, the door is already wide open for a theory of consciousness which, like a higher-order theory, explains an episode's consciousness in terms of the subject's awareness of the episode, but unlike a higher-order theory, explains an episode's consciousness in terms of 
a certain intrinsic character. According to what is sometimes called a 'sameorder' theory of consciousness, an episode is conscious just in case it makes its subject aware of that very episode, as well as its other objects of awareness (Brentano 1874, Caston 2002, Hossack 2002, Kriegel 2009).

Is this still too sophisticated? No. A reflective human being might conceptually articulate the intentional self-directedness of experience in the form of a propositional judgement which self-ascribes the experience. But the reflexive awareness in which consciousness consists doesn't itself presuppose any rational capacities unavailable to other animals. As Ayers makes plausible in Chapter 4 of the book and elsewhere, awareness directed upon a concrete thing - in this case an episode of experience-is more basic than propositional knowledge.

Finally, the same-order theory in conjunction with the results of $\$ 2$ yields a response to our challenge regarding the epistemic significance of consciousness. For it follows that Ayers would be mistaken in suggesting, as he seems to suggest, that the non-conscious superblindsighted subject could be in states with the same content as paradigm perspicuous sense experience. If the content of perspicuous perception concerns only distal objects and their relations to the body and sense-organs, then the in-principle possibility of sameness of content is difficult to resist. But as I have already suggested, on the basis of a thought experiment, this fully realist account of perspicuity is inadequate. According to the right account, the content of perspicuous sense experience concerns temporal and causal relations borne to the very experience one is now undergoing. But now, according to our congenial theory of consciousness, for an episode to exhibit such reflexive directedness is just what is for the episode to be conscious. So perspicuity, properly understood, is sufficient for consciousness. The content of perspicuous perception simply cannot be replicated by unconscious perception. That is why primary seeing must be conscious.

\section{References}

Ayers, Michael 2019. Knowing and Seeing. Groundwork for a New Empiricism. Oxford: Oxford University Press.

Brentano, Franz 1973 [1874]. Psychology from an Empirical Standpoint. Transl. by Antos C. Rancurello, D.B. Terrell, and Linda McAlister. London: Routledge. (2nd ed., introduction by Peter Simons, 1995).

Caston, Victor 2002. "Aristotle on Consciousness." Mind 111, 751-815.

Hosssack, Keith 2002. "Self-Knowledge and Consciousness." Proceedings of the Aristotelian Society 102, 163-181. 
Kriegel, Uriah 2009. Subjective Consciousness: A Self-representational Theory. Oxford: Oxford University Press.

Moore, George Edward 1903. "The Refutation of Idealism." Mind 12, 433-452.

Rosenthal, David 2002. "Explaining Consciousness". In Philosophy of Mind: Classical and Contemporary Readings, edited by David J. Chalmers, Oxford: Oxford University Press, 109-131.

Russell, Bertrand 1984. Theory of Knowledge. The 1913 Manuscript. London: Routledge.

Strawson, Galen 20o9. Selves: An Essay in Revisionary Metaphysics. Oxford: Oxford University Press.

Textor, Mark 2017. Brentano's Mind. Oxford: Oxford University Press. 